\title{
Molecular characterization of salivary gland malignancy using the Smgb-Tag transgenic mouse model
}

\author{
Antti A Mäkitie ${ }^{1,2}$, Patricia Pintor dos Reis ${ }^{1}$, Shilpi Arora ${ }^{1}$, Christina MacMillan ${ }^{3,4}$, \\ Giles C Warner ${ }^{1}$, Mahadeo Sukhai ${ }^{1,5}$, Irving Dardick ${ }^{3}$, Bayardo Perez-Ordonez ${ }^{3,6}$, \\ Richard Wells ${ }^{1}$, Dale Brown ${ }^{2}$, Ralph Gilbert ${ }^{2,7}$, Jeremy Freeman ${ }^{6,8}$, Patrick Gullane ${ }^{2,7}$, \\ Jonathan Irish ${ }^{2,7}$ and Suzanne Kamel-Reid ${ }^{1,3,5,6,7}$
}

${ }^{1}$ Department of Cellular and Molecular Biology, Ontario Cancer Institute and Princess Margaret Hospital, The University Health Network, Toronto, Ontario, Canada; ${ }^{2}$ Department of Otolaryngology and Head and Neck Surgery, Princess Margaret Hospital, The University Health Network, Toronto, Ontario, Canada; ${ }^{3}$ Department of Laboratory Medicine and Pathobiology, University of Toronto, Toronto, Ontario, Canada; ${ }^{4}$ Department of Pathology and Laboratory Medicine, Mount Sinai Hospital, Toronto, Ontario, Canada; ${ }^{5}$ Department of Medical Biophysics, University of Toronto, Toronto, Ontario, Canada; ${ }^{6}$ Department of Pathology, The University Health Network, Toronto, Ontario, Canada ; ${ }^{7}$ Department of Otolaryngology, University of Toronto, Toronto, Ontario, Canada and ${ }^{8}$ Department of Otolaryngology and Surgical Oncology, Mount Sinai Hospital, Toronto, Ontario, Canada

\begin{abstract}
The molecular mechanisms underlying salivary gland tumorigenesis remain unclear. In order to identify genetic changes that occur during the development of invasive adenocarcinoma from normal salivary gland, we used the Smgb-Tag transgenic mouse model. This transgene induces the progressive development of dysplasia to invasive adenocarcinoma in the submandibular salivary gland. Gene expression patterns from 20 submandibular glands (two normal, nine dysplasia and nine adenocarcinoma samples) were assessed using a mouse $15 \mathrm{~K}$ cDNA array. Unsupervised hierarchical clustering was used to group gene expression based on 157 differentially expressed genes distinguishing between dysplasias and adenocarcinomas. Further analysis identified 25 significantly overexpressed and 28 underexpressed cDNA sequences in adenocarcinoma as compared to dysplasia. Differential expression of five genes (Lcn2, Ptn, Cd24a, Mapk6 and Rnps1) was validated by quantitative real-time RT-PCR in a total of $\mathbf{4 8}$ mouse salivary gland tissues (seven histologically normal, 13 dysplasias and 28 adenocarcinomas), including the 20 samples analyzed by cDNA arrays. Immunohistochemical analysis was used to validate the expression of Ptn and Cd24a at the protein level in a subset of 16 mouse salivary glands (four normal, five dysplasia and seven adenocarcinoma samples), as well as in 23 human submandibular gland tumors (16 pleomorphic adenomas, three adenoid cystic carcinomas, one acinic cell carcinoma, one adenocarcinoma NOS, one myoepithelial and one mucoepidermoid carcinoma). We thus demonstrated that the Smgb-Tag transgenic mouse model is a useful tool for the identification of genes that are deregulated in salivary gland adenocarcinomas. Our data suggest that Ptn and Cd24a may be genetic markers associated with salivary gland tumorigenesis and/or progression.
\end{abstract}

Laboratory Investigation (2005) 85, 947-961. doi:10.1038/labinvest.3700288; published online 9 May 2005

Keywords: salivary gland; adenocarcinoma; transgenic mouse; carcinogenesis; gene expression; microarrays

Salivary gland tumors are a heterogeneous and relatively rare class of head and neck cancer, with several histologically diverse subtypes, such as

Correspondence: Dr S Kamel-Reid, PhD, 610 University Avenue, Room 9-622, Princess Margaret Hospital, Ontario Cancer Institute, University of Toronto, Toronto, Ontario, Canada.

E-mail: Suzanne.Kamel-Reid@uhn.on.ca

Received 21 October 2004; revised 17 March 2005; accepted 21 March 2005; published online 9 May 2005 carcinoma ex-pleomorphic adenomas, adenoid cystic carcinomas (ACC), mucoepidermoid carcinomas (MECA) and acinic cell carcinomas (AcCA). ${ }^{1}$ Risk factors may include external radiation to the head and neck, viral infection, and exposure to carcinogens. ${ }^{2}$ The morphological origin and clinical behavior of these tumors differ from the majority of other head and neck tumors, which are squamous cell carcinomas; their genetic origins remain to be elucidated. 
Recently, global gene expression profiling has allowed investigation of genetic changes associated with such poorly understood tumors, assessing the expression of thousands of genes simultaneously. Microarrays have recently been used to understand the molecular basis of tumor initiation and progression in breast cancer, ${ }^{3}$ meningiomas, ${ }^{4}$ soft tissue tumors ${ }^{5}$ and head and neck squamous cell carcinomas. ${ }^{6-10}$

Earlier reports of genetic alterations in human salivary gland malignancy focused on cytogenetic abnormalities, molecular changes involving large chromosomal regions, or a few selected genes. ${ }^{11-16}$ However, little is known about genome-wide expression changes and their correlation with the development and progression of human salivary gland tumors. Only a few reports have used microarrays to examine deregulated gene expression in human salivary gland tumors. Microarray studies have identified distinct gene expression profiles between papillary cystadenoma lymphomatosum and pleomorphic adenoma (PA), ${ }^{17}$ ACC vs normal salivary gland samples, ${ }^{18}$ and targets of the PLAG1 (Pleomorphic adenoma gene) proto-oncogene in PAs of salivary gland. ${ }^{19}$ These studies were performed using various different subtypes of human salivary gland tumors. In our study, by using a transgenic mouse model of salivary gland malignancy, we sought to minimize the genetic heterogeneity due to the analysis of multiple subtypes of this tumor, by focusing on only one subtype.

Transgenic mouse models of cancer allow a detailed understanding of the biology of tumor development and progression, and have been widely used for the identification of genes and pathways associated with human cancer. ${ }^{20,21}$ The completion of the mouse, Mus musculus, genome sequence has greatly contributed to the genomic analysis of cancer using mouse models. ${ }^{22}$ For example, transgenic mouse models have recently been used to study genetic changes associated with human astrocytomas, ${ }^{23}$ as well as acute promyelocytic leukemia. $^{24,25}$

Previously, one of us worked with a transgenic mouse line (Smgb-Tag) that develops submandibular gland adenocarcinoma of intercalated duct origin. ${ }^{26}$ In these mice, the oncogene SV40T antigen (Tag) is expressed from the neonatal submandibular gland secretory protein-b (Smgb) gene promoter. Expression of Tag within the salivary gland results in the development of gland dysplasia in all animals by $3-$ 4 months of age. This disease progresses to invasive salivary gland carcinoma in $>50 \%$ of male mice by the age of 12 months. We thus reasoned that the Smgb-Tag mice could serve as a good model to study the molecular genetic events involved in the development and progression of the salivary duct adenocarcinoma.

Our aim was to correlate histological progression of disease with gene expression, in order to identify genes associated with salivary gland tumor deve- lopment and progression. We identified a subset of differentially expressed genes in murine submandibular gland adenocarcinoma as compared to dysplasia. The identification of such genetic differences may allow us to further understand human salivary gland tumorigenesis using mouse model systems.

\section{Materials and methods}

\section{Transgenic Mice and Animal Care}

The Smgb-Tag transgenic mouse line expresses the Tag from the $S m g b$ gene promoter, and exhibits progression of normal submandibular gland to dysplasia and to invasive adenocarcinomas. ${ }^{26}$ Mice were maintained at the Animal Resource Center of the Ontario Cancer Institute/Princess Margaret Hospital, Toronto, Ontario, Canada. All animal experiments were performed in accordance with the Public Health Service Policy on Humane Care and Use of Laboratory Animals. Mice were sacrificed at the first sign of illness (ie, weight loss, loss of appetite or lethargy).

\section{Diagnosis of Salivary Gland Abnormalities}

Dysplastic ducts showed accumulation of cells with enlarged, hyperchromatic nuclei and readily identifiable mitoses. Ductal in situ carcinomas were diagnosed when clusters of dysplastic glands were evident. These clusters exhibited increased accumulation of atypical cells, but without invasion or replacement of the surrounding gland parenchyma. Invasive carcinoma was defined when adjacent parenchyma was replaced by proliferation of malignant cells and/or when the supporting stroma was invaded by the same cells.

\section{Harvesting and Fixation of Mouse Submandibular Glands}

Mouse submandibular glands were dissected at various time points. Samples were collected in duplicate: one piece was sent for histopathological examination, while the other was snap-frozen in liquid nitrogen and subsequently used for RNA extraction and microarray analysis. For histopathological analysis, we used two fixation procedures. ${ }^{26}$ Samples were fixed in $10 \%$ neutral-buffered formalin or in methacarn $(10 \%$ acetic acid, $90 \%$ methanol) overnight at $4{ }^{\circ} \mathrm{C}$ and paraffin-embedded. Five micrometer sections were cut from the paraffin blocks and placed on slides using standard techniques. In order to determine the histopathological diagnosis, slides were stained with hematoxylin and eosin, and analyzed by a pathologist (CM) to ensure the presence of $>80 \%$ malignant cells in the adenocarcinoma glands. 


\section{RNA Extraction}

Salivary gland tissues were homogenized and total RNA was extracted using a guanidinium isothiocyanate-acid phenol procedure (TRIZOL LS Reagent, GIBCO BRL, Rockville, MD, USA), and purified on a Qiagen mini-column (Qiagen, Valencia, CA, USA). RNA quantity was determined by spectrophotometry and quality by electrophoresis on a $1 \%$ denaturing formaldehyde agarose gel. ${ }^{27}$ RNA from all samples was found to be suitable for cDNA microarray analysis.

\section{cDNA Microarrays}

cDNA microarrays were performed on 20 mouse salivary gland tissue samples, including two histological normal, nine dysplasia and nine adenocarcinoma samples. Mouse 15K1 cDNA arrays containing 15286 sequences and 314 control spots were purchased from the Microarray Centre, Ontario Cancer Institute, University Health Network, Toronto, ON, Canada. Information regarding the $15 \mathrm{~K} 1$ clone set is available at http://www.microarrays.ca/ support/glists.html. Labelling and hybridization were performed as previously described. ${ }^{9}$ Gene fluorescence intensities were quantified using GenePix Pro 3.0 software (Axon Instruments, Foster City, CA, USA). Scatter plots of the Cy3 and Cy5 fluorescence intensities were evaluated in order to confirm that the Cy5/Cy3 fluorescence intensity ratios were consistent between experiments. Cy3 and Cy5 channels were normalized based on the average intensity for each subarray, and target sample/reference ratios were calculated for each spot. Experimental replicates with reciprocal fluorochrome labelling were performed for each sample and the expression ratio for each gene on the 15K1 array was averaged.

\section{Data Normalization}

Cy3 and Cy5 channels were normalized using the Normalize Suite (v.1.63) software package (www. utoronto.ca/cancyto). This method normalizes sections of the array rather than the whole array, thus compensating for variations in background. The mean background intensity was subtracted from mean foreground, excluding differences in background, flagged spots, saturated spots, and ghost spots (with less than $50 \%$ intensity) across the array. Duplicate spot intensities were averaged. Experimental replicates with reciprocal fluorochrome labelling were performed for each tumor sample. The replicate expression ratio for each gene was averaged.

\section{Clustering}

In order to cluster gene expression across the 20 experimental samples, data were quantified using
Imagene (Biodiscovery) software version 5 (http:// www.biodiscovery.com/imagene.asp) and analyzed by hierarchical Eisen Cluster. ${ }^{28}$ In this analysis, only genes that were present in $>80 \%$ of the samples and with at least two- fold over- or underexpression were included. Unsupervised Average Linkage Hierarchical Clustering was applied to arrange both genes and samples into groups. Cluster of samples (dendogram) and cluster of gene expression were visualized using Tree View.

\section{Significance Analysis of Microarrays (SAM)}

In order to reduce the false discovery rate and to identify statistically significant differentially expressed genes among normal, dysplasia and adenocarcinoma samples, we applied SAM (http:// www-stat.stanford.edu/ tibs/SAM/index.html).

\section{Validation of Microarray Data}

\section{Quantitative real-time RT-PCR}

Validation of microarray results was performed in a total of 48 mouse salivary gland tissues, including the 20 samples analyzed by cDNA microarrays. Quantitative real-time RT-PCR was performed using the ABI Prism 7700 Sequence Detection System (PE Applied Biosystems), and SYBR Green I, following our previously reported protocol. ${ }^{29}$ This fluorescent dye binds to the doublestranded DNA, allowing the quantitative detection of products during amplification by the polymerase chain reaction. Data were quantified and analyzed using Sequence Detection System software (version 1.7) from $P E$ Applied Biosystems. The relative quantification of target gene expression in unknown samples was accomplished by measuring the cycle number (Ct), at which the amount of amplified target reaches a fixed threshold is related to the amount of starting target; the higher the starting copy number of template, the fewer number of cycles it takes to reach a point in which the fluorescence is first recorded as statistically significant above background. In this analysis, $2 \mu \mathrm{g}$ total RNA from each sample were used for reverse-transcription in a $20 \mu \mathrm{L}$ reaction volume. Subsequently, $1 \mu \mathrm{L}$ of the RT product was used for PCR amplification. We quantified the expression of the structural gene $\beta$ actin as an internal control, which allowed normalization of the amount of starting cDNA in the reactions.

\section{Analysis of Quantitative Real-Time RT-PCR Results}

\section{$\Delta 4 C t$ method}

The relative quantification of the test and reference samples was determined from Ct values in duplicate for each target and internal control gene ( $\beta$-actin). $\Delta \mathrm{Ct}$ values were calculated for each sample, as 
follows: Duplicate Ct values were averaged and subtracted to obtain $\Delta \mathrm{Ct}[\Delta \mathrm{Ct}=\mathrm{Ct}$ (target gene) $-\mathrm{Ct}$ $(\beta$-actin)]. Relative expression levels were determined to be $2^{-\Delta \Delta \mathrm{Ct}}$, where $\Delta \Delta \mathrm{Ct}=\Delta \mathrm{Ct}$ (target sample) $-\Delta \mathrm{Ct}$ (reference sample). For the reference sample, $\Delta \Delta \mathrm{Ct}$ equals zero, and $2^{\circ}$ equals one, so there is no change in the reference sample expression, by definition. For the unknown samples, evaluation of $2^{-\Delta \Delta \mathrm{Ct}}$ indicates the fold change in gene expression relative to the reference sample. ${ }^{30}$

\section{Standard Curve}

A standard curve was constructed, using five serial dilutions of cDNA synthesized from $2 \mu \mathrm{g}$ of mouse universal RNA (standards). Dilutions of cDNA were used to ensure that amplification efficiencies of target and internal control genes were similar. Reactions were not considered in the analysis and were repeated if a correlation coefficient of less than 0.99 was obtained.

\section{Genes and Primers}

Five of the 53 genes identified by SAM analysis (Ptn, Cd24a, Lcn2, Rnps1, Mapk6; see Tables 1 and 2) were selected for validation. These five genes were selected because they were the most significantly differentially expressed. Using bioinformatics tools and international databases (eg http:// www.ncbi.nlm.nih.gov/LocusLink), we determined whether these genes could potentially play an important role in tumorigenesis. cDNA sequences described in these databases were used to design primers, using Primer Express software (version 1.5) (PE Applied Biosystems, Foster City, CA, USA). Primer and cDNA sequences were subjected to BLAST searches (www.ncbi.nlm.nih.gov/BLAST) to confirm identity and specificity, and are available upon request.

\section{PCR Amplification}

Reaction mixtures contained cDNA reverse transcribed from $2 \mu \mathrm{g}$ total RNA from each sample and from mouse universal RNA (Stratagene, Vancouver, BC, Canada), $10 \mu \mathrm{M}$ of each primer and $12.5 \mu \mathrm{l}$ of $2 \mathrm{X}$ SYBR Green I PCR Master Mix (PE Applied Biosystems), including SYBR Green I, 0.5 units of AmpErase uracyl-N-glycosylase (UNG), 1.25 units of Ampli-Taq Gold DNA polymerase, and $200 \mu \mathrm{M}$ dNTPs. Thermal cycling conditions were $50^{\circ} \mathrm{C}$ for $2 \mathrm{~min}$ (for UNG enzyme activity), $95^{\circ} \mathrm{C}$ for $10 \mathrm{~min}$, and 40 cycles at $95^{\circ} \mathrm{C}$ for $15 \mathrm{~s}$ followed by $60^{\circ} \mathrm{C}$ for $1 \mathrm{~min}$. Each assay included five dilutions of mouse universal cDNA and a nontemplate control. Experiments were performed in duplicate for each sample in the same reaction plate and repeated when a coefficient of variation higher than $5 \%$ was observed. Target genes and the $\beta$-actin internal control gene were amplified in the same reaction plate.

\section{Immunohistochemistry}

Immunohistochemical analysis was performed for protein products of two genes (Ptn and Cd24a), for which quantitative real-time RT-PCR showed consistent results and for which antibodies were commercially available. Unfortunately, commercial antibody was not available for Lcn2.

\section{Immunostaining for Ptn and Cd24a in Salivary Gland Tissue Sections}

In all, $4-5 \mu \mathrm{m}$ thick sections were cut from paraffinembedded tissue blocks. Immunohistochemical staining for Ptn and Cd24a was performed using the Avidin-Biotin method following standard protocols. ${ }^{31}$ Briefly, slides were deparaffinized in xylene, hydrated, then incubated with $0.5 \%$ $(\mathrm{v} / \mathrm{v}) \mathrm{H}_{2} \mathrm{O}_{2}$ in methanol for $20 \mathrm{~min}$, to block any endogenous peroxidase activity. Slides were then washed with Tris-Buffered Saline (TBS) and heated for $15 \mathrm{~min}$ at $100^{\circ} \mathrm{C}$ in $10 \mathrm{mM}$ sodium citrate buffer ( $\mathrm{pH}$ 6.0) for antigen retrieval. Sections were incubated with primary antibody against mouse and human Ptn (H-75; stock $200 \mathrm{ng} / \mu \mathrm{l}$; diluted 1:300) or Cd24a (FL-80 stock $200 \mathrm{ng} / \mu \mathrm{l}$, diluted 1:300) in antibody diluent (Dako Co., CA, USA) for $16 \mathrm{~h}$ at $4^{\circ} \mathrm{C}$. Both the primary antibodies were obtained from Santa Cruz Biotechnology Inc., CA, USA. The primary antibody was detected using Avidin-Biotin complex by the ABC method using the Dako LSAB plus kit (Dako Co., CA, USA). The color was developed using diaminobenzidine (DAB) as the chromogen. The slides were washed with TBS, three times for $5 \mathrm{~min}$ each after every step. Finally, the slides were counterstained with Mayer's hematoxylin and mounted with D.P.X. mountant. For negative controls, the appropriate antibody was omitted and either the antibody diluent alone or isotype-matched IgG serum was used.

\section{Positive Criteria for Immunohistochemical Staining}

Tissue sections were graded as $\mathrm{Ptn}$ and $\mathrm{Cd} 24 \mathrm{a}$ immunopositive if $\geq 10 \%$ of the cells showed cytoplasmic staining. Ptn and Cd24a expression in the tissue sections was evaluated using a semiquantitative scoring system: 0 for absent or detectable immunostaining in $<10 \%$ cells, +1 for $10-30 \%$ positive cells, +2 for $31-60 \%$ positive and +3 for $>60 \%$ positive cells. The immunostaining was evaluated in five areas of the slide sections for correlation and confirmation of the tissue analysis. 
Table 1 Classification by function of the 53 significantly differentially expressed genes in adenocarcinoma vs dysplasias of submandibular gland in transgenic mice

Transcription factor/nucleotide biosynthesis

[H3075H08] Mus musculus DNA for TATA binding protein

[H3026B01] Mus musculus domesticus transcription factor IID (Tbp)

[H3113H06] Mus musculus mRNA for KIAA0396 protein

[H3143F12] Mus musculus CTP synthetase homolog (CTPsH)

[H3110H03] Mus musculus SMAR1, mRNA

[H3126G09] Mus musculus E2F-like transcriptional repressor protein

DNA/RNA binding and metabolism

[H3022C08] Mus musculus ribonucleic acid binding protein S1 (Rnps1)

[H3047C07] Mus musculus zinc finger RNA binding protein (Zfr), mRNA

[H3031F02] Mouse mRNA for RNA polymerase I-associated factor (PAF53)

[H3108C09] Homo sapiens epididymis-specific, whey-acidic protein type, putative ovarian carcinoma marker (HE4)

[H3099E03] Mouse 15 K cDNA Clone Set Mus musculus cDNA clone H3099E03 5'

[H3097G03] Mouse $15 \mathrm{~K}$ cDNA Clone Set Mus musculus cDNA clone gi | 31742746 | gb | BG071346.2 | [31742746]

[H3103A03] Homo sapiens PRO2047 protein (PRO2047)

[H3073G07] Mus musculus mRNA for granzyme M

Cell growth and maintainence/cell cycle regulation/intracellular signalling cascade

[H3076D10] Mouse normal c-myc gene and translocated homologue from J558 plasmocytoma cells

[H3053G07] Mus musculus serine/threonine kinase AIE1 gene

[H3108E02] Homo sapiens mitogen-activated protein kinase 6 (MAPK6)

[H3153D05] Rattus norvegicus diacylglycerol kinase 90kDa (Dagk)

[H3124A02] Mus musculus pleiotrophin gene (Ptn)

Cell adhesion/matrix interaction

[H3009G08] Rattus norvegicus mu-protocadherin

[H3151A04] Mouse $15 \mathrm{~K}$ cDNA Clone Set Mus musculus cDNA (integrin alpha 6)

[H3075C03] Mus musculus claudin 10 (Cldn10)

Cytoskeleton organization

[H3106B04] Mus musculus SM22 alpha gene, 5' region and exon 1

Protein/protein interactions

[H3025C01] Homo sapiens mRNA for KIAA0697 protein

Transport

[H3055D11] Mus musculus FXYD domain-containing ion transport regulator 3 (Fxyd3)

[H3112E02] Mus musculus DNA for alpha globin gene and flanking regions

[H3083G02] Mus musculus 24p3 gene (Lcn2, lipocalin 2 gene)

Defense response

[H3109A05] Mus musculus Cd24a gene

Unknown

[H3106B01] Mus musculus cDNA clone gi | 12567450 | gb | BG084798.1 | [12567450]

[H3137H11] Mus musculus cDNA clone gi | 12569862 I gb | BG087298.1 |[12569862]

[H3111A04] Mus musculus adult male cecum cDNA, RIKEN full-length enriched library, clone 9130232E19 EST

[H3106B01] Mus musculus cDNA clone gi | 12567450 | gb | BG084798.1 | [12567450]

[H3111A04] Mus musculus cDNA clone gi | 12567841 |gb | BG085277.1|[12567841]

[H3065E11] Mus musculus cDNA clone gi | 12564040 | gb | BG081472.1 | [12564040]

[H3137H11] Mus musculus cDNA clone gi | 12569862 | gb | BG087298.1 |[12569862]

[H3110H03] Mus musculus cDNA clone gi | 12567833 | gb | BG085269.1 | [12567833]

[H3107H02] N/A

[H3085B02] Mus musculus cDNA clone gi | 12565724 | gb | BG083156.1 |[12565724]

[H3126D04] Mus musculus cDNA clone gi | 12569013 I gb | BG086449.1 | [12569013]

[H3066H12] Mus musculus cDNA clone gi | 12564164 I gb | BG081596.1 | [12564164]

[H3031D06] Mus musculus cDNA clone gi | 12561306 | gb | BG078738.1 | [12561306]

[H3089H10] Homo sapiens KIAA1048 protein (KIAA1048), mRNA

[H3007E08] Mus musculus cDNA clone gi | 12559444 I gb I BG076875.1 | [12559444]

[H3064B07] Mus musculus cDNA clone gi | 12563919| gb | BG081351.1 |[12563919]

[H3032G03] Mus musculus cDNA clone gi I 12548131 I gb | BG065568.1 | [12548131]

[H3070D08] N/A

[H3126B09] Mus musculus cDNA clone gi | 12556281 | gb | BG073624.1 |[12556281]

[H3056F05] Mus musculus cDNA clone gi | 12563273 | gb | BG080782.1 | [12563273]

[H3087C05] N/A

[H3084D06] Mus musculus cDNA clone gi | 12565657 |gb | BG083089.1 | [12565657]

[H3146B12] Mus musculus cDNA clone gi | 12570461 | gb | BG087897.1 | [12570461]

[H3110B04] Mus musculus cDNA clone gi | 12567794 I gb | BG085230.1 | [12567794]

[H3096H03] N/A

[H3097E03] Mouse mRNA for adipocyte p27 protein

[H3106H03] Mus musculus p8 protein (P8-pending)

[H3151A04] Mus musculus cDNA clone gi | 12570840 |gb | BG088276.1 |[12570840]

[H3096G05] Mus musculus cDNAclone gi| 12566702 | gb | BG084138.1 | [12566702]

Green represents underexpression and red, overexpression of genes in the adenocarcinomas relative to dysplasias.

N/A: Source clone ID only. 
Table 2 Function and mapping information of the five genes selected for validation

\begin{tabular}{llccl}
\hline Unigene ID & Gene symbol/name & $\begin{array}{c}\text { Mouse } \\
\text { chromosome }\end{array}$ & $\begin{array}{c}\text { Human } \\
\text { chromosome }\end{array}$ & Function \\
\hline Mm. 9537 & Lcn2/lipocalin 2 & 2B & $9 \mathrm{q} 34$ & $\begin{array}{l}\text { Binding/transport of small hydrophobic } \\
\text { molecules }\end{array}$ \\
Mm. 3063 & Ptn/pleiotrophin & $6 \mathrm{~B} 1$ & $7 \mathrm{q} 33-\mathrm{q} 34$ & $\begin{array}{l}\text { Growth-associated protein, signalling molecule } \\
\text { with putative role in apoptosis and bone } \\
\text { formation }\end{array}$ \\
Mm. 6417 & & $10 \mathrm{~B} 2$ & $6 \mathrm{q} 21$ & Cell surface antigen/defense response \\
Mm. 1951 & $\begin{array}{l}\text { Cd24a/Cd24a antigen } \\
\text { Rnps1/ribonucleic acid } \\
\text { binding protein S1 }\end{array}$ & 17A3.3 & $16 \mathrm{p} 13.3$ & $\begin{array}{l}\text { Nucleic acid binding protein/may play a role in } \\
\text { regulation of splicing and transcription }\end{array}$ \\
Mm. 18856 & $\begin{array}{l}\text { Mapk6/mitogen-activated } \\
\text { protein kinase 6 }\end{array}$ & 9D & $15 q 21$ & $\begin{array}{l}\text { Protein kinase, plays a role in signalling } \\
\text { regulating cell division }\end{array}$
\end{tabular}

\section{Results}

\section{Histological Findings}

Smgb-Tag transgene expression results in submandibular gland tumor development and progression in this mouse model. Early dysplastic changes were seen in the salivary gland by 2.5 months of age, and adenocarcinoma by 10-12 months. ${ }^{26}$ Salivary gland adenocarcinomas developed in $\sim 50 \%$ of male mice and $<1 \%$ of female mice. Transgenic mice exhibited abnormalities only in submandibular glands. No histological changes were observed in the parotid or sublingual glands, or in any other organs.

Histology of the submandibular glands ranged from normal (Figure 1a) to dysplasia (Figure 1b) to invasive adenocarcinoma of the intercalated ducts (Figure 1c), and correlated with the age of the mouse. All invasive carcinomas showed large islands and sheets of tumor cells that contained glandular lumens, and many of them exhibited foci of necrosis. Most tumors were moderately differentiated; however, some were poorly differentiated, with a solid growth pattern and occasional areas of spindled cells, reminiscent of sarcomatoid carcinoma. Mice with invasive adenocarcinomas also showed duct dysplasia and carcinoma in situ in adjacent submandibular gland tissue. Malignant cells showed moderate pleomorphism with hyperchromatic nuclei and an increased number of mitoses. Their cytoplasm was lightly eosinophilic and/or slightly granular, however, neither acinic cells nor mucinous differentiation were identified.

\section{cDNA Microarray Results}

Mouse 15K1 cDNA arrays were used to determine the gene expression profiles of two histologically normal salivary glands, nine dysplastic lesions, and 9 invasive salivary gland adenocarcinomas harvested from transgenic mice. Results were analyzed using unsupervised hierarchical Eisen clustering. This method organizes genes and experiments into groups, and may be used to delineate clinically relevant patterns in a diverse set of samples. ${ }^{32}$ Clustering was based on 157 differentially expressed genes distinguishing between dysplasias and adenocarcinomas. Three salivary gland dysplasias (25D, 26D and 27D) clustered together with the adenocarcinomas (Figure 2). Further histological analysis of these dysplasias revealed that they also contained a small region of carcinoma in situ, in addition to dysplastic intercalated ducts. As the whole tissue sample was processed and used for microarray analysis, it is likely that the presence of a mixed cellular population is responsible for these dysplasias being more similar to the adenocarcinomas. Both histologically normal samples ( $10 \mathrm{~N}$ and $32 \mathrm{~N}$ ) clustered together with the dysplasias (Figure 2). This observation suggested that the histologically normal tissues were more similar to the dysplasias than to the adenocarcinomas.

Further statistical analysis using SAM identified 53 genes as being statistically significantly deregulated between adenocarcinomas and dysplasias. Of these, 25 were overexpressed and 28 were underexpressed in carcinomas, relative to dysplasias. These sequences were classified as growth factors, mitogen-activated protein kinases, transmembrane and cell-cell signalling proteins, transcription factors, cell surface antigens, and cytoskeleton-associated proteins (Table 1), based on functional annotation using the Nucleotide, LocusLink and Unigene tools from NCBI (http://www.ncbi.nlm. nih.gov/). Several of these proteins are involved in mechanisms crucial to tumor biology, such as angiogenesis, apoptosis, and metastasis. In addition, a number of ESTs of unknown function with significantly deregulated expression were also detected. 

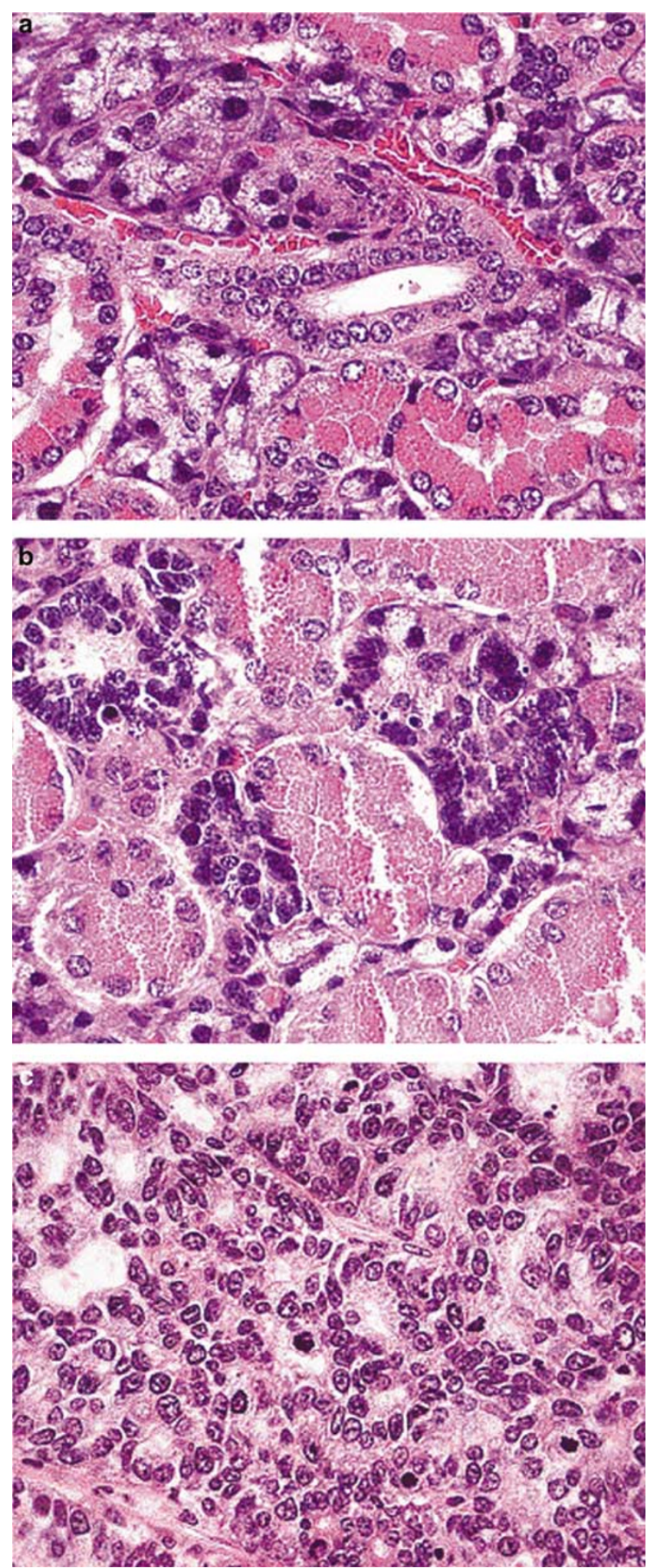

Figure 1 Histological characteristics of mouse salivary gland samples obtained from the transgenic mouse line Smgb-Tag, which develops submandibular gland adenocarcinoma of intercalated duct origin: (a) normal, (b) dysplasia, and (c) adenocarcinoma. Magnification: $\times 400$

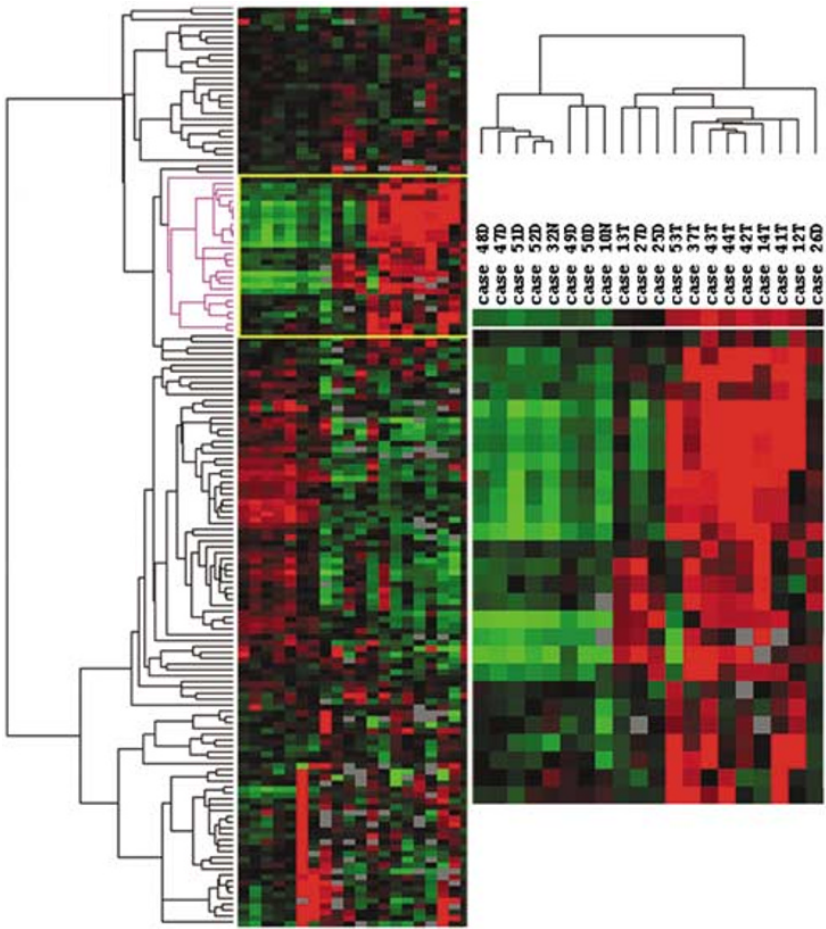

Figure 2 Dendogram obtained by hierarchical clustering of the 20 mouse salivary gland samples. Tree view represents the genes that best distinguish between the distinct histological samples (normal, dysplasia, and adenocarcinomas). The gene cluster highlighted contains the genes most differentially expressed (including the five genes used for validation) between normal, dysplasia and adenocarcinoma samples.

\section{Validation of Gene Expression}

\section{Quantitative real-time RT-PCR}

We selected five genes for validation by quantitative real-time RT-PCR: lipocalin 2 ( $L c n)$, pleiotrophin (Ptn), Cd24a antigen (Cd24a), mitogen-activated protein kinase 6 (Mapk6) and ribonucleic acidbinding protein S1 (Rnps1). Criteria for selection included gene function, potential involvement in malignancy, presence of human homologues, and statistically significant differential expression levels between dysplasias and adenocarcinomas (Table 2). Validation was performed in all 20 mouse salivary gland samples analyzed by cDNA array, and in an additional 28 mouse salivary gland samples (five histologically normal glands, four dysplasias and 19 adenocarcinomas). Differential expression of Lcn2, Ptn, Cd24a, Mapk6, and Rnps1 was validated in all 13 dysplasias and 28 adenocarcinomas. The overexpressed genes Ptn and Lcn2 showed higher relative expression in carcinomas $(6.49 \pm 6.80,45.28 \pm 46.71$, respectively), compared to dysplasias $(3.77 \pm 2.31,11.28 \pm 19.48$, respectively) and normal samples $(0.46 \pm 0.76,1.44 \pm 1.17$, respectively), confirming our microarray data. These differences in expression were statistically significant for Ptn $(P=0.027)$ and Lcn2 $(P=0.019)$ confirming our observation that normal samples 
showed the lowest mean expression level, followed by dysplasias and adenocarcinomas. Overexpression of $C d 24 a$ was confirmed in all dysplasias and adenocarcinomas as compared to normal samples; however, dysplasias showed higher expression levels $(26.33 \pm 10.7)$ compared to adenocarcinomas (14.6 \pm 8.64$)$ (Figure 3).

Mapk6 and Rnps1 were underexpressed in all normal tissues, dysplasias and carcinomas as compared to the universal control RNA, as detected by quantitative real-time RT-PCR. These results did not validate our cDNA microarray data, which showed underexpression of these two genes in adenocarcinomas and no change in dysplasias (Figure 3). Although real-time PCR is a very sensitive and reliable method for gene expression quantification, we did not proceed with further validation of Mapk6 and Rnps1 expression.

\section{Immunohistochemistry}

Having observed, at the mRNA level, overexpression of Ptn, Lcn2, and Cd24a in dysplasias and adenocarcinomas, we sought to further validate our array results at the protein level using immunohistochemistry. We randomly selected 16/48 mouse salivary gland samples for immunohistochemical analysis: four normal tissues, five dysplasias, and seven adenocarcinomas. Normal mouse salivary glands were used as controls in all experiments. Ptn immunostaining was not detected in any normal tissue section (Figure 4a, Table 3), while 4/5 dysplastic lesions and 7/7 carcinomas were Ptn immunopositive (Figure $4 \mathrm{~b}$ and c, respectively; Table 3). Ptn immunoreactivity was localized to the cytoplasm of the ductal cells. Occasional nuclear staining was also observed.

Cd24a staining was detected in 2/4 normal mouse salivary glands (Figure 4d, Table 3), 4/5 dysplasias and $7 / 7$ carcinomas (Figure 4e and 3f, respectively; Table 3). Normal salivary glands showed less intense staining compared to dysplasias and carcinomas. Cd24a was predominantly localized to the cytoplasm of duct cells; occasional expression was seen in the extracellular matrix.

Ptn and Cd24a protein expression was also examined in a subset of 23 human submandibular gland tumors (16 PAs, three ACCs, one AcCA, one adenocarcinoma not otherwise specified (AdenoNOS), one myoepithelial carcinoma (MCA), and one mucoepidermoid carcinoma (MECA). Normal salivary gland tissue was present in the majority of sections adjacent to the tumor. In all normal tissue sections examined, Ptn and Cd24a expression were present in the cytoplasm of intercalated ductal cells; in the majority of normal tissues, expression of both proteins was observed in $10-30 \%$ of cells and graded as +1 . In human tumor samples, Ptn and Cd24a immunostaining was localized to the cytoplasm of ductal cells. Ptn expression was observed in $30-60 \%$ of cells (graded as +2 ) in $8 / 16 \mathrm{PA}, 1 / 3$ ACC, and 1/1 MECA. Ptn was expressed in $>60 \%$ of cells (graded as +3 ) in 6/16 PA, 2/3 ACC, and 1/1 AcCA. Cd24a was expressed in $30-60 \%$ of cells in $1 /$ 2 AdenoNOS; $>60 \%$ of cells showed Cd24a expression in 16/16 PA, 3/3 ACC, 1/1 AcCA, 1/1 MCA, and 1/1 MECA. These data are summarized in Table 4.

The majority of human samples analyzed were PAs, a benign salivary gland tumor. PA samples showed higher expression levels of Cd24a when compared to Ptn levels. The observation of higher expression levels of $\mathrm{Cd} 24 \mathrm{a}$ in benign tumors agrees with our real-time PCR data in the mouse samples, which showed higher levels of Cd24a expression in dysplasias compared to carcinomas. However, Cd24a expression levels were also higher than Ptn expression levels in the MCA and MECA samples. Therefore, in order to confirm overexpression of these proteins and to determine whether this alteration is correlated with different tumor subtypes, it is necessary to analyze a larger sample set, including several malignant submandibular gland tumors, as well as normal salivary gland tissues from patients with diagnosis of conditions other than cancer. We are assuming that tissue adjacent to the tumor is normal; this may not be true from a genetic perspective. Figures 5 and 6 show representative examples of Ptn (Figure 5a-f) and Cd24a (Figure 6a-f) staining in human salivary gland tissues. Histologically, normal salivary gland adjacent to tumor shows Ptn and Cd24a staining in intercalated ducts. These two proteins showed high levels of expression in PA, ACC, AcCA, AdenoNOS, MCA, and MECA compared to histologically normal samples.

\section{Discussion}

Salivary gland neoplasms are a diverse group of tumors with a spectrum of histological appearance, degree of differentiation and clinical behavior. Although benign lesions can usually be controlled by surgical excision, malignant lesions remain a therapeutic challenge. In all, $50 \%$ of salivary gland neoplasms are malignant ${ }^{33}$ and in addition to surgical morbidity, malignant lesions have a high rate of local recurrence. ${ }^{34}$ Thus, it is important to identify genetic markers useful to distinguish benign and malignant lesions. Identification of deregulated genes may help increase effectiveness of therapeutic intervention and lead to development of new therapeutic options for salivary gland adenocarcinomas, which have been treated primarily using surgical approaches. As it is difficult to obtain fresh tissue samples representative of disease progression in humans, animal models of salivary gland tumorigenesis are ideally suited for such studies. One of us previously characterized the Smgb-Tag transgenic mouse line and we sought to assess its utility as a model for studying the 

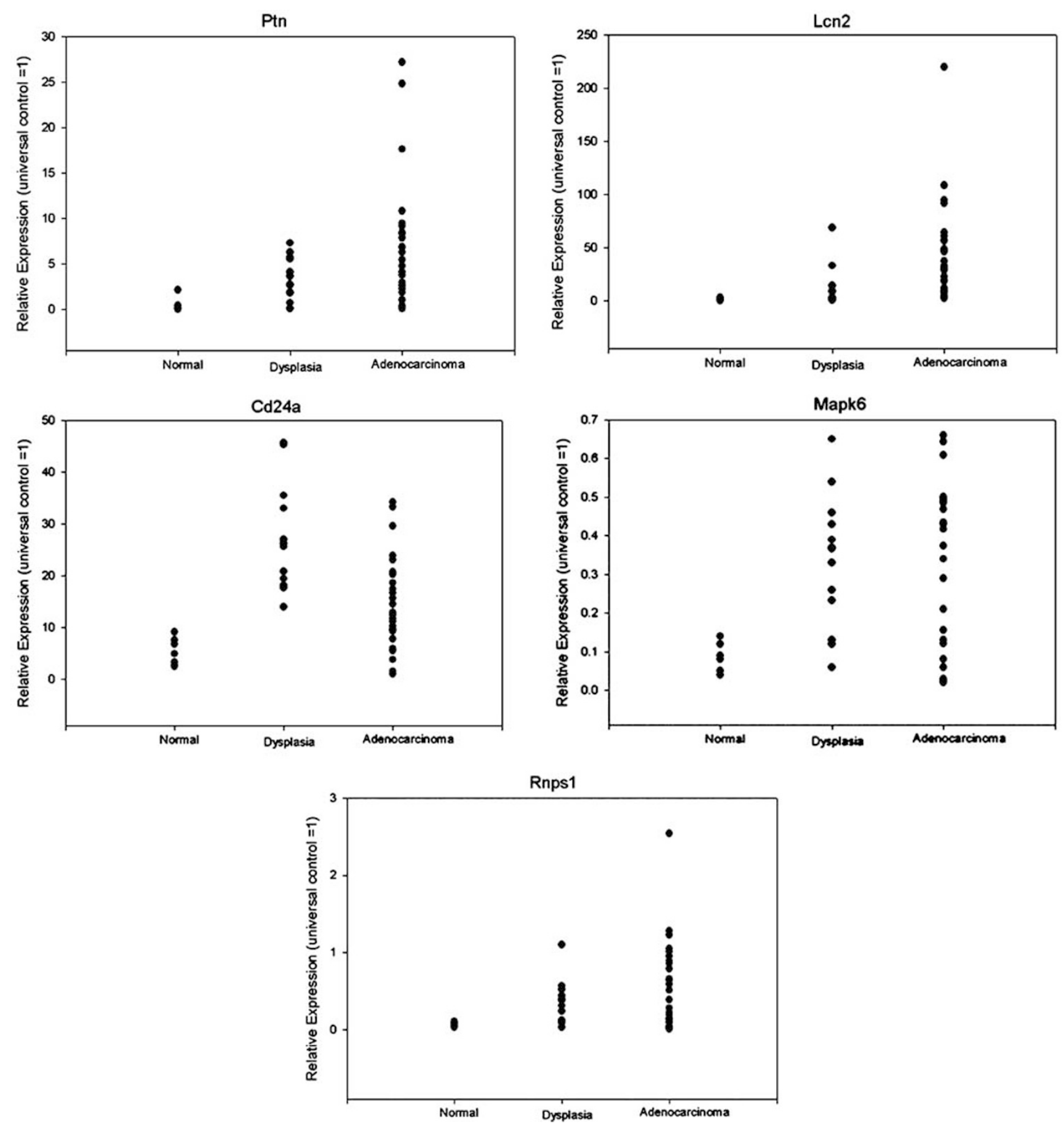

Figure 3 Comparison between the relative expression levels of the five validated genes in the normal, dysplastic, and adenocarcinomas mouse samples, as detected by quantitative real-time PCR. The baseline sample is mouse universal RNA, with expression level equal to 1.

development and progression of salivary gland adenocarcinomas. $^{26}$

Tumorigenesis in the $S m g b$-Tag mouse model is a multistep process involving intercalated duct cells. Hyperplasia of these ducts is apparent in 30-day-old mice, progressing to dysplasia by 3-4 months of age and marked dysplasia and carcinoma in situ at 4-6 months of age. Adenocarcinoma is observed in
$>50 \%$ of the adult male Smgb-Tag mice by 12 months of age. The oncogene Tag is detected in submandibular glands of 3-day-old mice and persists exclusively in altering intercalated duct cells, carcinomas in situ and adenocarcinomas. SmgbTag mouse submandibular gland tumors resemble human adenocarcinoma, not otherwise specified (NOS), a not uncommon neoplasm. Immunohisto- 

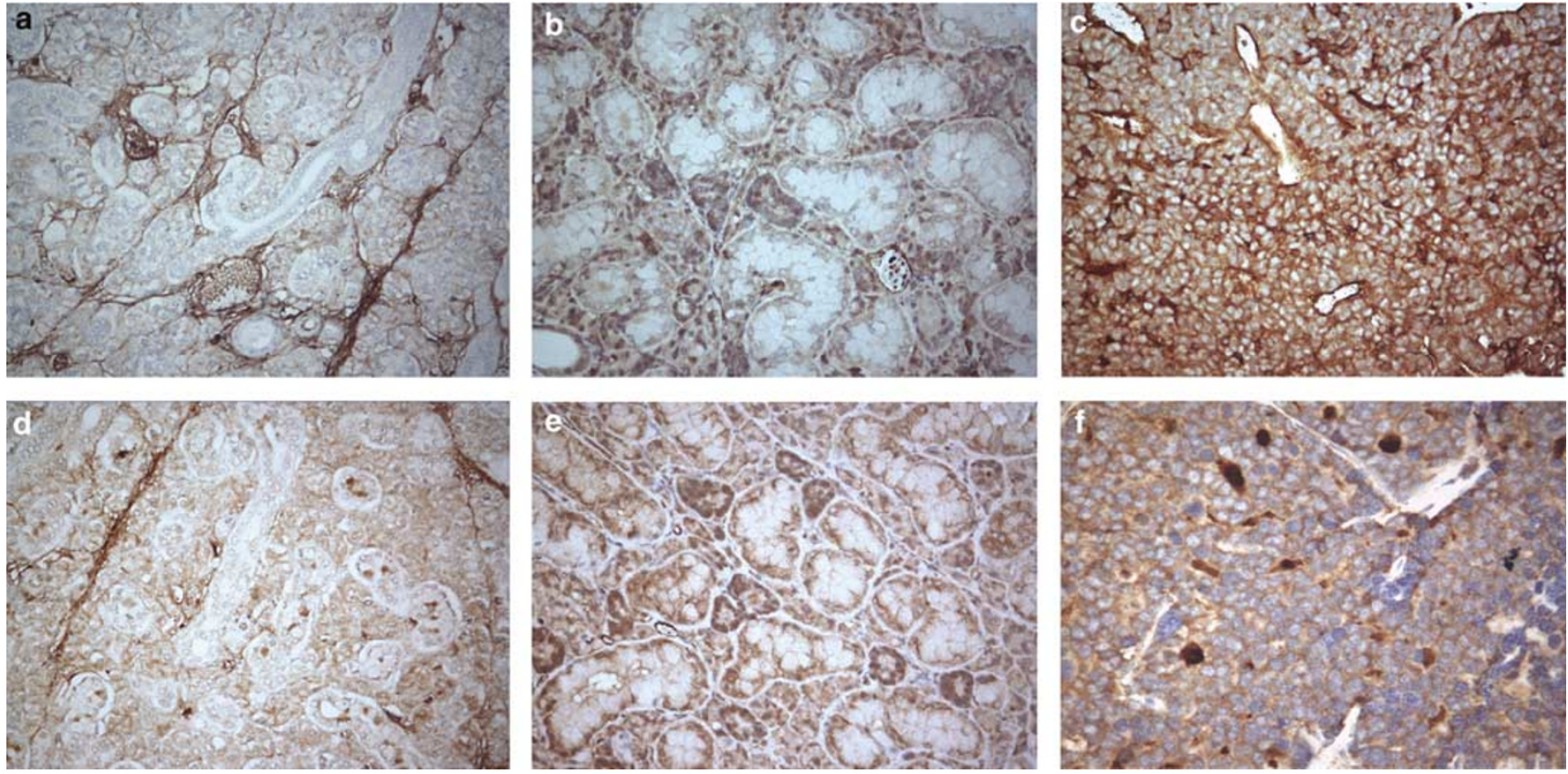

Figure 4 Representative immunostaining for Ptn and Cd24a staining in mouse salivary gland tissues. (a) and (d): histologically normal mouse salivary gland, showing no expression of Ptn and Cd24a, respectively, in the ductal cells; some Cd24a staining was seen in the extracellular matrix. (b) and (e): dysplastic salivary gland showing the ductal cells with cytoplasmic staining of Ptn and Cd24a, respectively. (c) and (f): adenocarcinoma showing strong cytoplasmic expression of Ptn and Cd24a, respectively. Magnification: $\times 250$.

Table 3 Comparison between the quantitative real-time RT-PCR and immunohistochemistry results in normal, dysplastic, and adenocarcinoma samples from the Smgb-Tag transgenic mice

\begin{tabular}{|c|c|c|c|c|}
\hline \multirow{2}{*}{$\begin{array}{l}\text { Mouse \# } \\
\text { Normal }\end{array}$} & \multicolumn{2}{|c|}{$Q-R T-P C R$} & \multicolumn{2}{|c|}{ Immunohistochemistry } \\
\hline & $\begin{array}{l}\text { Cd24a fold } \\
\text { change }\end{array}$ & $\begin{array}{l}\text { Ptn fold } \\
\text { change }\end{array}$ & $\begin{array}{c}C d 24 \\
\text { intensity } \\
\text { scoring }\end{array}$ & $\begin{array}{c}\text { Ptn } \\
\text { intensity } \\
\text { scoring }\end{array}$ \\
\hline 10 & 6.79 & 2.18 & +2 & 0 \\
\hline 32 & 4.92 & 0.23 & 0 & 0 \\
\hline 5 & 3.33 & 0.046 & 0 & 0 \\
\hline 001 & 7.59 & 0.15 & +1 & 0 \\
\hline \multicolumn{5}{|c|}{ Dysplasia } \\
\hline 25 & 20.8 & 1.92 & +1 & 0 \\
\hline 26 & 18.12 & 5.75 & +2 & +1 \\
\hline 27 & 14.02 & 6.32 & 0 & +1 \\
\hline 47 & 26.2 & 7.31 & +1 & +2 \\
\hline 51 & 45.7 & 2.7 & +2 & +1 \\
\hline \multicolumn{5}{|c|}{ Adenocarcinoma } \\
\hline 12 & 5.93 & 6.91 & +1 & +1 \\
\hline 13 & 12.42 & 4.78 & +1 & +2 \\
\hline 14 & 10.26 & 2.59 & +1 & +1 \\
\hline 37 & 20.67 & 3.79 & +2 & +1 \\
\hline 42 & 29.6 & 8.48 & +2 & +3 \\
\hline 43 & 12.9 & 9.48 & +2 & +2 \\
\hline 44 & 34.2 & 8.36 & +2 & +1 \\
\hline
\end{tabular}

Intensity scoring: 0 for $<10 \%$ cytoplasmic expression; +1 for $10-30 \%$ positive cells; +2 for $31-60 \%$ positive cells; and +3 for $>60 \%$ positive cells.

chemical and ultrastructural findings indicate that intercalated duct cells are the source for carcinoma in situ and adenocarcinomas. ${ }^{26}$ With the occasional tumor cell having zymogen granules, the mouse submandibular gland tumors also reflect the human microcystic variant of AcCA, which mainly differentiate into the neoplastic equivalent of intercalated duct cells. ${ }^{35}$

There are a few instances of duct cell hyperplasia, dysplastic phenomena or in situ carcinoma occurring in human salivary gland tumors. For example, presence of dysplasia and carcinoma in situ in $\mathrm{PAs},{ }^{36}$ ductal dysplasia and intraductal carcinoma in salivary duct carcinoma, ${ }^{37}$ hyperplasia of parotid gland intercalated ducts in epithelial-MCAs, ${ }^{38,39}$ compact foci of intercalated duct-like structures in benign and malignant tumors, ${ }^{40}$ and hyperplasia of striated ducts basal cells and formation of microadenomas in membranous basal cell adenomas. ${ }^{41}$ Such ductal changes and evidence of dysplasia in certain human neoplasms indicates that this transgenic mouse model has relevance for human salivary gland neoplasia.

While there are a number of other models of salivary gland malignancy, few studies examining gene expression profiles of salivary gland tumor progression using mouse models exist. For example, Tilli et $a l^{42}$ showed that the mechanism regulating the reversal of early-stage salivary gland dysplasia is cellular differentiation mediated by phosphorylation of $D P-1$ (differentiation-related transcription factor-1 polypeptide-1). One other study assessed the gene expression profiles of human ACCs of the salivary gland and compared it to normal salivary glands. ${ }^{18}$ The authors identified several genes overexpressed in carcinomas, including Sox 4 and $A P 2 \alpha$ 
Table 4 Immunohistochemical analysis results of Ptn and Cd24a expression in 23 human submandibular gland tumors

\begin{tabular}{lcc}
\hline $\begin{array}{l}\text { Histopathological diagnosis/ } \\
\text { sample number }\end{array}$ & $\begin{array}{c}\text { PTN intensity } \\
\text { scoring }\end{array}$ & $\begin{array}{c}\text { CD24a intensity } \\
\text { scoring }\end{array}$ \\
\hline
\end{tabular}

\begin{tabular}{|c|c|c|}
\hline \multicolumn{3}{|c|}{ Pleomorphic adenoma } \\
\hline $1^{*}$ & +3 & +3 \\
\hline 4 & +2 & +3 \\
\hline 5 & +2 & +3 \\
\hline 7 & +2 & +3 \\
\hline 8 & +2 & +3 \\
\hline 9 & +3 & +3 \\
\hline 10 & +1 & +3 \\
\hline 11 & +2 & +3 \\
\hline 13 & +2 & +3 \\
\hline 16 & +3 & +3 \\
\hline 18 & +3 & +3 \\
\hline 19 & +2 & +3 \\
\hline 20 & +3 & +3 \\
\hline 21 & +1 & +3 \\
\hline 22 & +3 & +3 \\
\hline 23 & +2 & +3 \\
\hline \multicolumn{3}{|c|}{ Adenoid cystic carcinoma } \\
\hline 2 & +3 & +3 \\
\hline 3 & +2 & +3 \\
\hline 15 & +3 & +3 \\
\hline \multicolumn{3}{|c|}{ Acinic cell carcinoma } \\
\hline 14 & +3 & +3 \\
\hline \multicolumn{3}{|c|}{ Adenocarcinoma NOS } \\
\hline 12 & +1 & +2 \\
\hline \multicolumn{3}{|c|}{ Myoepithelial carcinoma } \\
\hline 6 & +1 & +3 \\
\hline \multicolumn{3}{|c|}{ Mucoepidermoid carcinoma } \\
\hline 17 & +2 & +3 \\
\hline
\end{tabular}

The majority of histologically normal tissues adjacent to tumor showed Ptn and Cd24a expression in $10-30 \%$ of cells and were scored as +1 .

*recurrent tumor.

Intensity scoring: +1 for $10-30 \%$ positive cells; +2 for $31-60 \%$ positive cells; +3 for $>60 \%$ positive cells.

(transcription factors), laminin $\beta 1$ and Type $I V$ collagen $\alpha 1$ (extracellular matrix and basement membrane components) and Cyclin D1 (cell cycle regulator). In contrast to this study, Cyclin D1 and Type IV collagen $\alpha 1$ expression were not altered in salivary gland dysplasias or adenocarcinomas in our microarray experiments.

We report overexpression of Ptn and Cd24a, and their potential involvement in salivary gland malignancy. Our results for Ptn agree with its described function as an extracellular matrix-associated protein with mitogenic and angiogenic activities. ${ }^{43}$ Pleiotrophin is expressed in several normal tissues, including tongue, larynx and lung (http://www. ncbi.nlm.nih.gov/UniGene/ESTProfileViewer.cgi?uglist $=$ Hs.371249). Its overexpression has been reported to enhance bone formation and growth in transgenic mice. ${ }^{44}$ In addition, a functional study investigating a panel of angiogenesis-related factors in a transgenic mouse model that develops mammary tumors, showed that Ptn is a potential candidate for angiogenesis-related metastasis. ${ }^{45}$ Comparative genomic hybridization and spectral karyotyping analyses revealed that $7 \mathrm{q} 33-\mathrm{q} 34$, containing Ptn, is frequently gained in carcinomas of colon, kidney, parathyroid gland, pancreas, among others (http:// www.ncbi.nlm.nih.gov/sky/webcghdrawing.cgi).

Ptn encodes heparin-binding growth factor 8 and neurite growth-promoting factor 1 , and is a paracrine growth and angiogenic factor produced by glioma cells, contributing to their malignancy. ${ }^{46}$ Ptn is essential for the growth of melanoma cells. ${ }^{47}$ Its overexpression has been associated with progression of pancreatic carcinoma ${ }^{48,49}$ and lung cancer, ${ }^{50}$ and considered an adverse prognostic marker in hepatocellular carcinoma. ${ }^{51}$ In a recent microarray study of a diverse group of salivary gland tumors, Ptn was highly expressed in PA compared to normal salivary gland. ${ }^{52}$ In our study, as Ptn expression increased with disease stage in mice, it may play a similar role in salivary gland tumorigenesis, leading to the development of more aggressive tumors.

Cd24a encodes for the Cd24 antigen (small cell lung carcinoma cluster 4 antigen), a heavily glycosylated glycosylphosphatidylinositol-linked cell surface protein, expressed in several tissues, including colon, larynx, lung, breast, skin, and tongue (http://www.ncbi.nlm.nih.gov/UniGene/ESTProfile Viewer.cgi?uglist $=$ Hs.375108). The human homologue maps to $6 q 21$, a region frequently involved in copy number gains in colon carcinoma NOS, kidney, parathyroid gland, pancreas, lung and other carcinomas (http://www.ncbi.nlm.nih.gov/sky/ webcghdrawing.cgi).

Overexpression of $C d 24 a$ has been associated with reduced disease-free survival of ovarian cancer patients ${ }^{53,54}$ and it has been detected as an independent prognostic marker in non-small-cell lung cancer. ${ }^{55}$ Furthermore, its high expression has been associated with invasiveness in breast cancer cell lines. ${ }^{56} \mathrm{Cd} 24 \mathrm{a}$ expression could be significant for tumor invasion and dissemination via the blood stream and the retention of cells in organs via its ability to interact with endothelial cells. ${ }^{57}$ We observed overexpression of $\mathrm{Cd} 24 \mathrm{a}$ in dysplasias and adenocarcinomas; its expression was higher in dysplasias as compared to adenocarcinomas. Our observation that $\mathrm{Cd} 24 \mathrm{a}$ is higher in dysplasias suggests that its overexpression might be necessary for the dysplastic cells to invade the underlying stromal tissue, leading to the development of adenocarcinoma.

Although is not known if Ptn and Cd24a interact in common pathways, it is interesting to note that their functions are similar, and that they are both overexpressed in salivary gland adenocarcinoma. It is possible that these two proteins are not primary etiological factors in tumorigenesis, but instead are markers of an as-yet-unidentified upstream event. 

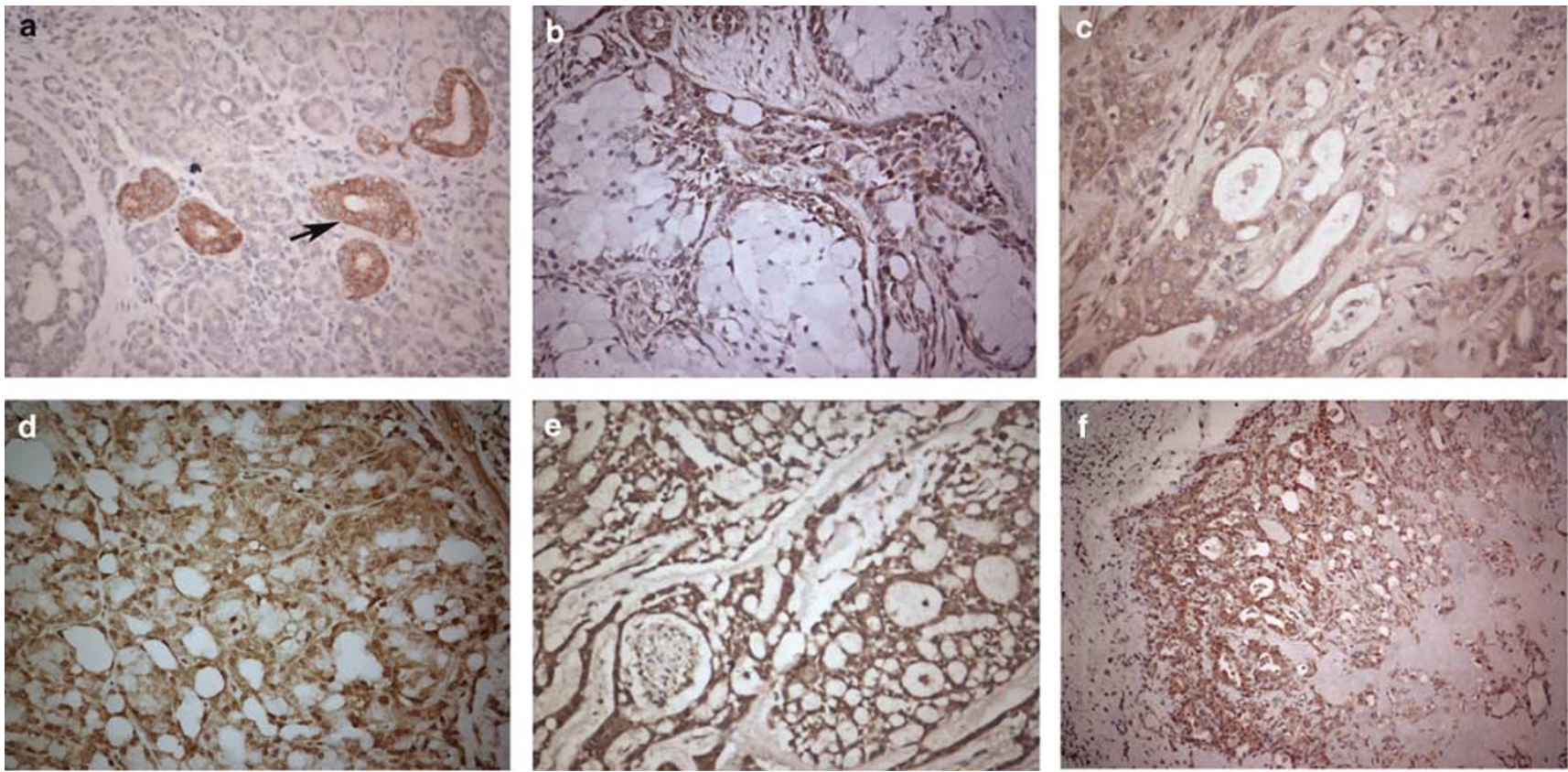

Figure 5 Representative immunostaining for Ptn in human submandibular gland tumors. (a): histologically normal salivary gland in an area adjacent to an ACC, showing Ptn staining specific to intercalated ducts, as indicated by the arrow. (b): MECA showing cytoplasmic staining of Ptn predominantly in the intermediate cells. (c): adenocarcinoma NOS, showing cytoplasmic staining of Ptn. (d): AcCA with microcystic architecture; showing Ptn staining in acinar cells, intercalated ductular cells and glandular cells, NOS. (e): ACC with perineural invasion; Ptn expression is observed in ductal and myoepithelial cells. (f): PA showing Ptn staining in ductal and myoepithelial cells. Magnification: $\times 250$, except for $(\mathbf{f}): \times 100$.
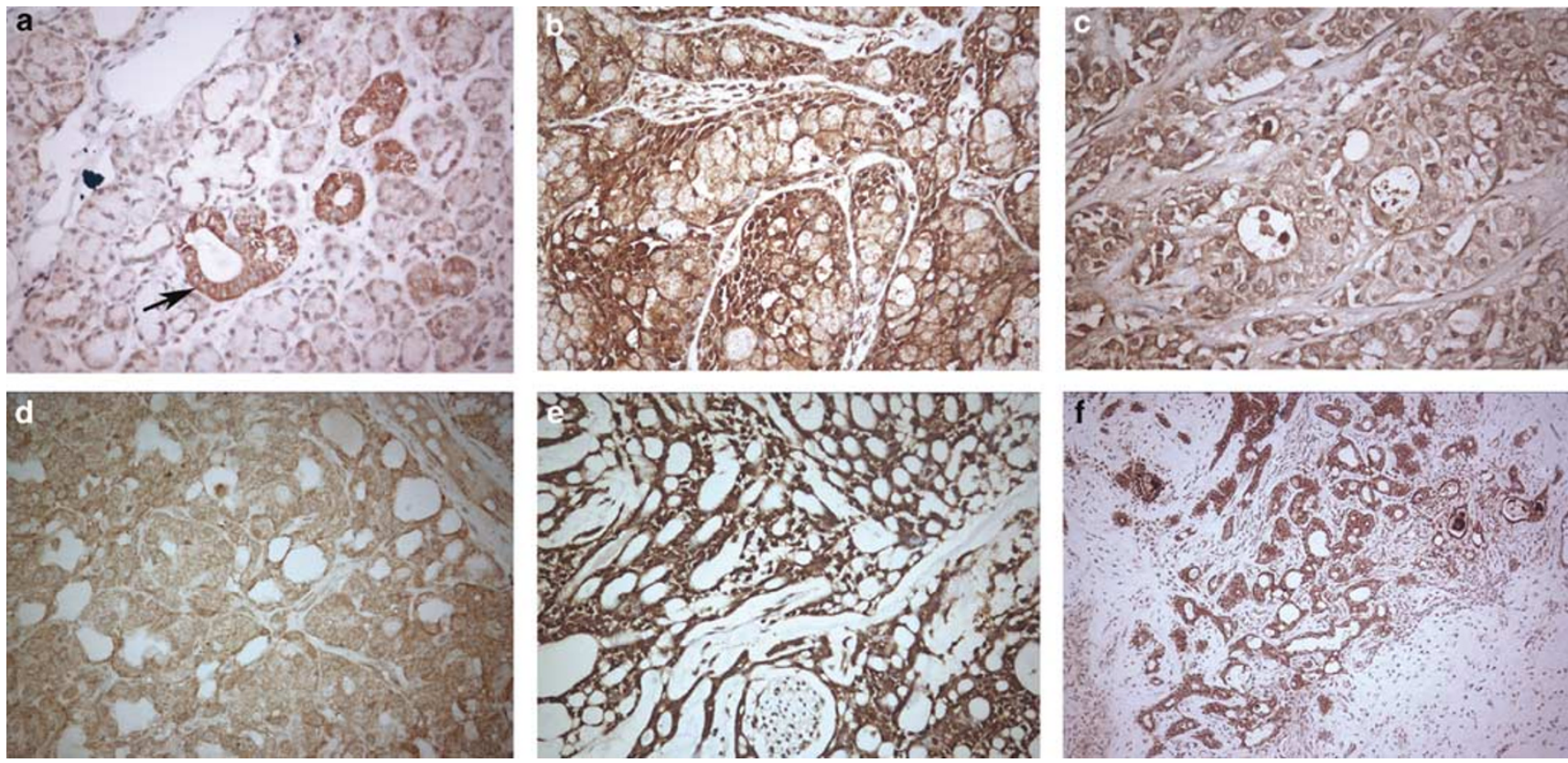

Figure 6 Representative immunostaining for Cd24a in human submandibular gland tumors. (a): histologically normal salivary gland in an area adjacent to a PA, showing Cd24a staining specific to intercalated ducts, as indicated by the arrow. (b): MECA showing cytoplasmic staining of Cd24a predominantly in the intermediate cells. (c): adenocarcinoma NOS, showing cytoplasmic staining of CD24a. (d): AcCA with microcystic architecture; showing Cd24a staining in acinar cells, intercalated ductular cells and glandular cells, NOS. (e): ACC with perineural invasion; Cd24a expression is observed in ductal and myoepithelial cells. (f): PA showing Cd24a staining in ductal and myoepithelial cells. Magnification: $\times 250$, except for $(\mathbf{f}): \times 100$.

Identification of this putative event becomes important in understanding the underlying mechanisms of salivary gland malignancy.
In order to examine Ptn and Cd24a expression in human salivary gland tumors, we performed immunohistochemical analysis of 23 submandibular 
gland tumor samples. The majority of human samples analyzed were PAs, which showed higher expression levels of Cd24a when compared to Ptn. Of the 23 tumor samples, one AcCA (sample \#14) with a predominantly microcystic architecture but also with solid and follicular patterns was studied. This tumor contained intercalated ductular cells and glandular cells, NOS, reminiscent of the glandular cells observed in many of the Smgb-Tag mice tumors. This tissue showed high expression levels of Ptn and Cd24a, with staining in all of the architectural patterns and cell types present, including the intercalated ductular and glandular NOS type tumor cells.

In the majority of cases, histologically normal tissue adjacent to tumor showed Ptn and Cd24a expression in $10-30 \%$ of intercalated ductal cells. Although histologically normal, tissue adjacent to tumor can harbor genetic alterations. It is therefore necessary to examine Ptn and Cd24a expression levels in normal salivary gland tissues biopsied from patients without cancer. Our preliminary data suggest that Ptn and Cd24a are overexpressed in human salivary gland tumors, although these results need to be verified in a larger sample set, including several types of malignant submandibular gland tumors as well as normal salivary gland tissue from patients without cancer. Studies such as these will allow us to draw more definitive conclusions on the involvement of these two genes in human tumors.

We were unable to validate the deregulation of Lcn2 at the protein level due to lack of a commercially available antibody. Lcn2 is an oncogene involved in cell cycle regulation and belongs to a superfamily of proteins capable of transporting small molecules such as retinols and steroids. ${ }^{58}$ Its human homologue maps to 9q34 and is expressed in adult bone marrow, uterus, prostate, stomach, salivary gland, and other tissues. Lcn2 overexpression was reported in human pancreatic adenocarcinomas, ${ }^{59}$ and its protein has also been identified in the urine of patients with bladder cancer ${ }^{60}$ suggesting its importance as a tumor marker. Microarray analysis in a mouse model of hepatocellular carcinoma identified Lcn2 as a differentially expressed gene, and suggested that this gene may be an important marker for liver carcinogenesis and progression. ${ }^{61}$ Deregulation of Lcn2 thus may be an important genetic marker associated with salivary gland malignancy, although its role in tumor progression remains unclear.

We suggest that Ptn, Cd24a, and Lcn2 may constitute putative biomarkers of salivary gland malignancy. Functional analysis of these proteins as well as corollary studies in a larger number of human salivary gland tumors from different histological classifications and subsites are currently being performed in our laboratory, in order to elucidate the role of Ptn and Cd24a in human salivary gland tumorigenesis. These studies will also allow us to build correlations with relevant clinicopathological parameters and to determine whether deregulation of these genes is a primary or a secondary event in the formation of these tumors.

\section{Acknowledgements}

The authors wish to acknowledge Dr. Lily Mirels, Department of Molecular and Cell Biology, University of California, Berkeley, CA, USA for developing and providing the transgenic mouse model for this study. We thank Helen Zhang for her excellent technical assistance. This work was also supported by NCIC (013220) (SKR) and the Wharton Head \& Neck Cancer Research Funds (PG, JI), Finska Läkaresällskapet and the Finnish Medical Society Duodecim (AM) and the Temmy Latner/Dynacare Foundation (JF).

\section{References}

1 Speight PM, Barrett AW. Salivary gland tumours. Oral Dis 2002;8:229-240.

2 Dardick I. Salivary Gland Tumor Pathology. IgakuShoin Medical Publishers: New York, 1996.

3 Pusztai L, Ayers M, Stec J, et al. Gene expression profiles obtained from fine-needle aspirations of breast cancer reliably identify routine prognostic markers and reveal large-scale molecular differences between estrogen-negative and estrogen-positive tumors. Clin Cancer Res 2003;9:2406-2415.

4 Watson MA, Gutmann DH, Peterson K, et al. Molecular characterization of human meningiomas by gene expression profiling using high-density oligonucleotide microarrays. Am J Pathol 2002;161:665-672.

5 Nielsen TO, West RB, Linn SC, et al. Molecular characterisation of soft tissue tumours: a gene expression study. Lancet 2002;359:1301-1307.

6 Villaret DB, Wang T, Dillon D, et al. Identification of genes overexpressed in head and neck squamous cell carcinoma using a combination of complementary DNA subtraction and microarray analysis. Laryngoscope 2000;110:374-381.

7 Squire JA, Bayani J, Luk C, et al. Molecular cytogenetic analysis of head and neck squamous cell carcinoma: by comparative genomic hybridization, spectral karyotyping, and expression array analysis. Head Neck 2002;24:874-887.

8 Ha PK, Benoit NE, Yochem R, et al. A transcriptional progression model for head and neck cancer. Clin Cancer Res 2003;9:3058-3064.

9 Warner GC, Reis PP, Jurisica I, et al. Molecular classification of oral cancer by cDNA microarrays identifies overexpressed genes correlated with nodal metastasis. Int J Cancer 2004;110:857-868.

10 Macgregor PF, Squire JA. Application of microarrays to the analysis of gene expression in cancer. Clin Chem 2002;48:1170-1177.

11 Johns III MM, Westra WH, Califano JA, et al. Allelotype of salivary gland tumors. Cancer Res 1996;56:1151-1154.

12 Queimado L, Reis A, Fonseca I, et al. A refined localization of two deleted regions in chromosome $6 \mathrm{q}$ associated with salivary gland carcinomas. Oncogene 1998;16:83-88. 
13 Cerilli LA, Swartzbaugh JR, Saadut R, et al. Analysis of chromosome 9p21 deletion and p16 gene mutation in salivary gland carcinomas. Hum Pathol 1999;30: 1242-1246.

14 Morio T, Morimitsu Y, Hisaoka M, et al. DNA copy number changes in carcinoma in pleomorphic adenoma of the salivary gland: a comparative genomic hybridization study. Pathol Int 2002;52:501-507.

15 Hungermann D, Roeser K, Buerger H, et al. Relative paucity of gross genetic alterations in myoepitheliomas and myoepithelial carcinomas of salivary glands. J Pathol 2002;198:487-494.

16 Stallmach I, Zenklusen P, Komminoth P, et al. Loss of heterozygosity at chromosome 6q23-25 correlates with clinical and histologic parameters in salivary gland adenoid cystic carcinoma. Virchows Arch 2002;440: 77-84.

17 Francioso F, Carinci F, Tosi L, et al. Identification of differentially expressed genes in human salivary gland tumors by DNA microarrays. Mol Cancer Ther 2002;1: $533-538$.

18 Frierson Jr HF, El-Naggar AK, Welsh JB, et al. Large scale molecular analysis identifies genes with altered expression in salivary adenoid cystic carcinoma. Am J Pathol 2002;161:1315-1323.

19 Voz ML, Mathys J, Hensen K, et al. Microarray screening for target genes of the proto-oncogene PLAG1. Oncogene 2004;23:179-191.

20 Renou JP, Bierie B, Miyoshi K, et al. Identification of genes differentially expressed in mouse mammary epithelium transformed by an activated beta-catenin. Oncogene 2003;22:4594-4610.

21 Bonner AE, Lemon WJ, You M. Gene expression signatures identify novel regulatory pathways during murine lung development: implications for lung tumorigenesis. J Med Genet 2003;40:408-417.

22 Gregory SG, Sekhon M, Schein J, et al. A physical map of the mouse genome. Nature 2002;418:743-750.

23 Gutmann DH, Huang ZY, Hedrick NM, et al. Mouse glioma gene expression profiling identifies novel human glioma-associated genes. Ann Neurol 2002;51: 393-405.

24 He LZ, Tribioli C, Rivi R, et al. Acute leukemia with promyelocytic features in PML/RARalpha transgenic mice. Proc Natl Acad Sci U S A 1997;94:5302-5307.

25 Sukhai MA, Wu X, Xuan Y, et al. Myeloid leukemia with promyelocytic features in transgenic mice expressing hCG-NuMA-RARalpha. Oncogene 2004;23: $665-678$.

26 Dardick I, Ho J, Paulus M, et al. Submandibular gland adenocarcinoma of intercalated duct origin in SmgbTag mice. Lab Invest 2000;80:1657-1670.

27 Sambrook J, Fritch EF, Maniatis T. In: N Ford, C Nolan, M Ferguson (eds). Molecular Cloning: A Laboratory Manual. Cold Spring Harbor: New York, 1989.

28 Eisen MB, Spellman PT, Brown PO, et al. Cluster analysis and display of genome-wide expression patterns. Proc Natl Acad Sci USA 1998;95:1486314868.

29 Reis PP, Rogatto SR, Kowalski LP, et al. Quantitative real-time PCR identifies a critical region of deletion on $22 q 13$ related to prognosis in oral cancer. Oncogene 2002;21:6480-6487.

30 Livak KJ, Schmittgen TD. Analysis of relative gene expression data using real-time quantitative PCR and the 2(-Delta Delta C(T)) Method. Methods 2001;25: $402-408$.
31 Soni S, Mathur M, Shukla NK, et al. Stromelysin-3 expression is an early event in human oral tumorigenesis. Int J Cancer 2003;107:309-316.

32 Nagayama S, Katagiri T, Tsunoda T, et al. Genomewide analysis of gene expression in synovial sarcomas using a cDNA microarray. Cancer Res 2002;62:58595866.

33 Kaplan MD, Baum BJ. The functions of saliva. Dysphagia 1993;8:225-229.

34 Friedman M, Levin B, Grybauskas V, et al. Malignant tumors of the major salivary glands. Otolaryngol Clin North Am 1986;19:625-636.

35 Dardick I, George D, Jeans MT, et al. Ultrastructural morphology and cellular differentiation in acinic cell carcinoma. Oral Surg Oral Med Oral Pathol 1987;63: 325-334.

36 Brandwein M, Huvos AG, Dardick I, et al. Noninvasive and minimally invasive carcinoma ex mixed tumor: a clinicopathologic and ploidy study of 12 patients with major salivary tumors of low (or no?) malignant potential. Oral Surg Oral Med Oral Pathol Oral Radiol Endod 1996;81:655-664.

37 Delgado R, Klimstra D, Albores-Saavedra J. Low grade salivary duct carcinoma. A distinctive variant with a low-grade histology and a predominant intraductal growth pattern. Cancer 1996;78:958-967.

38 Di Palma S. Epithelial-myoepithelial carcinoma with co-existing multifocal intercalated duct hyperplasia of the parotid gland. Histopathology 1994;25: 494-496.

39 Chetty R. Intercalated duct hyperplasia: possible relationship to epithelial-myoepithelial carcinoma and hybrid tumours of salivary gland. Histopathology 2000;37:260-263.

$40 \mathrm{Yu}$ GY, Donath K. Adenomatous ductal proliferation of the salivary gland. Oral Surg Oral Med Oral Pathol Oral Radiol Endod 2001;91:215-221.

$41 \mathrm{Yu}$ GY, Ussmueller J, Donath K. Histogenesis and development of membranous basal cell adenoma. Oral Surg Oral Med Oral Pathol Oral Radiol Endod 1998;86:446-451.

42 Tilli MT, Hudgins SL, Frech MS, et al. Loss of protein phosphatase 2A expression correlates with phosphorylation of DP-1 and reversal of dysplasia through differentiation in a conditional mouse model of cancer progression. Cancer Res 2003;63:7668-7673.

43 Deuel TF, Zhang N, Yeh HJ, et al. Pleiotrophin: a cytokine with diverse functions and a novel signaling pathway. Arch Biochem Biophys 2002;397:162-171.

44 Tare RS, Oreffo RO, Sato K, et al. Effects of targeted overexpression of pleiotrophin on postnatal bone development. Biochem Biophys Res Commun 2002; 298:324-332.

45 Sugino T, Kusakabe T, Hoshi N, et al. An invasionindependent pathway of blood-borne metastasis: a new murine mammary tumor model. Am J Pathol 2002;160:1973-1980.

46 Mentlein R, Held-Feindt J. Pleiotrophin, an angiogenic and mitogenic growth factor, is expressed in human gliomas. J Neurochem 2002;83:747-753.

47 Satyamoorthy K, Oka M, Herlyn M. An antisense strategy for inhibition of human melanoma growth targets the growth factor pleiotrophin. Pigment Cell Res 2000;13(Suppl 8):87-93.

48 Weber D, Klomp HJ, Czubayko F, et al. Pleiotrophin can be rate-limiting for pancreatic cancer cell growth. Cancer Res 2000;60:5284-5288. 
49 Klomp HJ, Zernial O, Flachmann S, et al. Significance of the expression of the growth factor pleiotrophin in pancreatic cancer patients. Clin Cancer Res 2002;8: 823-827.

50 Jager R, List B, Knabbe C, et al. Serum levels of the angiogenic factor pleiotrophin in relation to disease stage in lung cancer patients. Br J Cancer 2002;86:858-863.

51 Qin LX, Tang ZY. The prognostic molecular markers in hepatocellular carcinoma. World J Gastroenterol 2002; 8:385-392.

52 Maruya S, Kim HW, Weber RS, et al. Gene expression screening of salivary gland neoplasms: molecular markers of potential histogenetic and clinical significance. J Mol Diagn 2004;6:180-190.

53 Welsh JB, Zarrinkar PP, Sapinoso LM, et al. Analysis of gene expression profiles in normal and neoplastic ovarian tissue samples identifies candidate molecular markers of epithelial ovarian cancer. Proc Natl Acad Sci USA 2001;98:1176-1181.

54 Kristiansen G, Denkert C, Schluns K, et al. CD24 is expressed in ovarian cancer and is a new independent prognostic marker of patient survival. Am J Pathol 2002;161:1215-1221.

55 Kristiansen G, Schluns K, Yongwei Y, et al. CD24 is an independent prognostic marker of survival in nonsmall cell lung cancer patients. Br J Cancer 2003;88: 231-236.
56 Schindelmann S, Windisch J, Grundmann R, et al. Expression profiling of mammary carcinoma cell lines: correlation of in vitro invasiveness with expression of CD24. Tumour Biol 2002;23:139-145.

57 Fogel M, Friederichs J, Zeller Y, et al. CD24 is a marker for human breast carcinoma. Cancer Lett 1999;143: 87-94

58 Chan P, Simon-Chazottes D, Mattei MG, et al. Comparative mapping of lipocalin genes in human and mouse: the four genes for complement C8 gamma chain, prostaglandin-D-synthase, oncogene24p3, and progestagen-associated endometrial protein map to HSA9 and MMU2. Genomics 1994;23: 145-150.

59 Terris B, Blaveri E, Crnogorac-Jurcevic $\mathrm{T}$, et al. Characterization of gene expression profiles in intraductal papillary-mucinous tumors of the pancreas. Am J Pathol 2002;160:1745-1754.

60 Monier F, Surla A, Guillot M, et al. Gelatinase isoforms in urine from bladder cancer patients. Clin Chim Acta 2000;299:11-23.

61 Meyer K, Lee JS, Dyck PA, et al. Molecular profiling of hepatocellular carcinomas developing spontaneously in acyl-CoA oxidase deficient mice: comparison with liver tumors induced in wild-type mice by a peroxisome proliferator and a genotoxic carcinogen. Carcinogenesis 2003;24:975-984. 